Article

\title{
Urban \& Online: Social Media Use among Adolescents and Sense of Belonging to a Super-Diverse City
}

\author{
Anne K. van Eldik *, Julia Kneer and Jeroen Jansz \\ Erasmus School of History, Culture and Communication, Erasmus University Rotterdam, 3000DR Rotterdam, \\ The Netherlands; E-Mails: vaneldik@eshcc.eur.nl (A.K.E.), kneer@eshcc.eur.nl (J.K.), jansz@eshcc.eur.nl (J.J.) \\ * Corresponding author
}

Submitted: 13 December 2018 | Accepted: 4 April 2019 | Published: 28 June 2019

\begin{abstract}
In a world of continuous migration, super-diverse cities consist of a multitude of migrants and non-migrants from a variety of cultural backgrounds. Yet one characteristic they all have in common is the place where they currently live. In addition, both groups are active users of social media, especially the young. Social media provide platforms to construct and negotiate one's identity-particularly the identity related to where one lives: urban identity. This article presents the results of a survey study ( $N=324$ ) investigating the relationships between social media engagement and identity construction among migrant and non-migrant adolescents in the super-diverse city of Rotterdam, the Netherlands. It was found that urban identity was significantly higher for migrants than non-migrants. Certain aspects of social media engagement predicted urban identity in combination with social identity. Finally, social media engagement was found to be positively related to group self-esteem.
\end{abstract}

\section{Keywords}

adolescents; identity construction; migration; Rotterdam; self-esteem; social media; super-diversity; urban identity

\section{Issue}

This article is part of the issue "Refugee Crises Disclosed: Intersections between Media, Communication and Forced Migration Processes", edited by Vasiliki Tsagkroni (Leiden University, The Netherlands) and Amanda Alencar (Erasmus University Rotterdam, The Netherlands).

(C) 2019 by the authors; licensee Cogitatio (Lisbon, Portugal). This article is licensed under a Creative Commons Attribution 4.0 International License (CC BY).

\section{Introduction}

In recent history, migration has resulted in the creation of a multi-cultural society. Ranging from forced to voluntary, at the end of their migration process many migrants find themselves in a multi-cultural environment. Newcomers often settle in cities which consequently increase in ethnic, cultural and socio-economic diversity. Vertovec (2007) has labelled this dynamic urban environment a super-diverse city, a concept that comes with many opportunities and challenges-from cultural richness to socio-economic inequalities and stereotyping. The concept of super-diversity is characterized by the idea that diversity should be viewed beyond ethnicity, and should also take into account a wide range of other factors (Vertovec, 2007). Its complexity covers not only elements such as country of origin and the details of one's migration history but also factors in their current social and living situation (Vertovec, 2007). While the super-diverse group of citizens possess a rich array of identities, there is one common characteristic: place. Previously discussed in many fields and from different points of view, place identity can be looked at from an urban perspective: urban identity (Lalli, 1992; Proshansky, 1978; Proshansky, Fabian, \& Kaminoff, 1983). As the city is a shared space and a shared part of its inhabitants' identity, the urban identity can be considered a connecting element, especially for migrants. We conducted our research in Rotterdam, a super-diverse city in the Netherlands. With 638,712 inhabitants it is the second largest city in the country and home to people from around 200 different nationalities and many different ethnic backgrounds 
(Jennissen, Engbersen, Bokhorst, \& Bovens, 2018; Statistics Netherlands, 2018a). Rotterdam was chosen not only due to its super-diverse character, but also for its position as a minority-majority city, and its articulated identity and (urban) youth culture (Fortuin \& van der Graaf, 2006; JongRRKC, 2008; Kanne \& van Engeland, 2019; OBI, 2018). Moreover, this city is located in the Netherlands, a country in which nearly everyone has internet access (Statistics Netherlands, 2018b; van Deursen \& Helsper, 2015).

Adolescence, particularly early adolescence, is an important period marked by rapid development, including identity (Delfos, 2013; Valkenburg \& Piotrowski, 2017). Answering the "Who am I?" question is particularly relevant in a super-diverse environment where adolescents have to make sense of their relations to groups with different identities. Research in different countries has shown that media use plays an important role in this development (boyd, 2014; Ito et al., 2010; Valkenburg \& Peter, 2011). Social media, as a shared space with limited parental interference and the strong presence of adolescent peers, affords socializing practices and the construction and negotiation of one's identity (boyd, 2014; Valkenburg \& Peter, 2011). Adolescents may use this space to deal with the intricate dynamic environment in which they find themselves and need to position themselves through different forms of social media engagement. The construction of identity, particularly in the context of a city, may create a sense of belonging, which in turn develops self-esteem.

In light of the super-diverse environment in which these adolescents find themselves, and the broader question of identity construction and a sense of belonging, our aim was to investigate the social media use of adolescents in the city and how this is related to a sense of belonging to the city through identity development. Moreover, we aimed to investigate the potential differences between migrant and non-migrant adolescents in terms of their social media use and identity development, and how these two are related to each other. Resulting from these aims, the research questions were:

RQ 1: To what extent does social media engagement influence identity development (in terms of social identity, urban identity, and self-esteem)?

RQ 2: To what extent do migrant and non-migrant adolescents differ concerning social media engagement and identity development?

Answering these questions helps to understand the role of social media in adolescents' everyday lives and its role in the social and psychological well-being of (migrant) adolescents. Moreover, it contributes to the body of knowledge on the role of the urban environment in the everyday life of adolescents, and its importance in making sense of themselves and their group in relation to others. Surveys were employed to explore the multiple relations between (social) media usage of our participants and their social and urban identities.

\section{Theoretical Framework}

\subsection{Social Media Use and Types of Engagement}

In this study, we conceptualize social media as online spaces, or platforms, that afford communication and the uploading and sharing of content and thus foster interaction and self-presentation (boyd \& Ellison, 2007; Carr \& Hayes, 2015). They include, but are not limited to, social networking sites, instant messaging platforms, apps for content sharing, and other content sharing platforms. On these platforms, one can share user-generated content, including in very mundane, everyday ways.

Social media are central to the everyday lives of many teens (boyd, 2014; Ito et al., 2010). Throughout the years, various social media platforms have come and gone, gaining and losing popularity. As research by Anderson and Jiang (2018) shows, whereas Facebook used to be most popular, the attention of teens has shifted to platforms such as YouTube, Instagram, and Snapchat. Research conducted in the Netherlands revealed that while Facebook is still popular among adolescents in the Netherlands, YouTube, Instagram, and Snapchat are challenging Facebook's popularity (Kennisnet, 2017).

Previous studies have identified various categories of social media engagement (Ito et al., 2010; Jansz, Slot, Tol, \& Verstraeten, 2015; Shao, 2009). Shao (2009) differentiates between consumption, participation, and production. Jansz et al. (2015) categorize communication as a separate type of engagement from participation. Studies have found that only a small number of people choose to engage actively (Kushner, 2016; Nielsen, 2006). Due to factors underlying the digital divide, it is more likely that it will be the more privileged minorities who create online content, resulting in material that is largely catered to those groups (Brake, 2014). Migrant adolescents might, therefore, be more inclined not to take part or might feel culturally underrepresented by content creators. However, as the internet has become more easily accessible, and as platform preferences have changed, thresholds for participation and production have lowered in an age of online content creation involving small, private audiences, such as those on Snapchat or Instagram. Adolescents can send pictures or videos to their friends through Snapchat but may choose not to upload public YouTube videos.

Positioning this in the context of our research, we first need to ask about what access migrant adolescents have to social media and the availability of digital devices, such as smartphones, computers, or tablets. We expect the following due to mainly socio-economic reasons (particularly material-, temporal- and social resources) of physical or material access (van Dijk, 2012):

H 1: Non-migrant adolescents have greater access to digital devices than migrant adolescents.

As a result, we need to question whether their social media use differs from that of non-migrant adolescents. 
Q 1: Do migrant and non-migrant adolescents differ in their social media engagement?

\subsection{Identity Development and Social Media Engagement}

Early adolescence is a period characterized by rapid social and psychological development, which includes the construction and development of the adolescent's identity (Delfos, 2013). Previous research has shown that social media plays an important role in the construction and negotiation of identity, where social media function as shared spaces where they can hang out with peers and explore the boundaries of their identities, with parents being mostly absent (boyd, 2014; Delfos, 2013; Valkenburg \& Peter, 2011).

Various forms of social media engagement may accommodate identity development. In terms of consumption, media idols play a crucial role. Media idols can function as role models, especially for adolescents because they prefer to identify with someone who is quite similar to them (Valkenburg \& Piotrowski, 2017). Due to the abundance of user-generated content and an increasing amount of social media influencers (SMIs), a diversity of role models have become available from and for different groups in society. Adolescents from different backgrounds may find SMIs who are similar to them, which helps reinforce their identities. In terms of participation and communication, adolescents can develop their social identity by communicating with peers and sharing their opinions in comments sections or by rating content (boyd, 2014; Ito et al., 2010). Finally, adolescents can express their identities by creating and sharing their own content (boyd, 2014; Ito et al., 2010). The online environment offers a place where adolescents can test boundaries in their social environment, seeking approval in the process, which helps them in building self-esteem and identity-an essential part of adolescent development (Valkenburg \& Piotrowski, 2017). Developing self-esteem is also saturated by social factors because it is embedded in the groups they belong to.

\subsection{Migrant Youth, Identity Formation, and New Media}

Previous studies on migrant adolescents and media have shown that media production can help construct and negotiate individual and collective identities (de Block \& Buckingham, 2007; de Leeuw \& Rydin, 2007; Leurs, Omerović, Bruinenberg, \& Sprenger, 2018). From a transnational point of view, research has argued that media afford migrants the opportunity to cross borders and maintain their connections with their (parents') country of origin, yet research shows that young migrants often focus more on their local environment, some creating hybrid identities in the process (Rydin \& Sjöberg, 2008). Such hybrid identities offer space for more than one place of belonging (de Leeuw \& Rydin, 2007; Rydin \& Sjöberg, 2008). This offers young migrants the oppor- tunity to identify with and have a sense of belonging to different places or cultures. Social media can thus play a crucial role in developing an identity and a sense of belonging, especially for adolescents with a migrant background who may have lost their city, family, culture, and with it, consequently, part of their identity.

\subsection{Urban Context, Migration, and Identity}

Rotterdam, as a super-diverse city, holds great ethnic, cultural and socio-economic diversity, which is partly a result of previous and continuous forms of migration. In 2018 there were 80,742 western migrants (12.6\%) and 244,109 non-western migrants (38.2\%) (Statistics Netherlands, 2018a). Rotterdam is so-called a majorityminority city, in which the majority of the citizens have a migration background from a large diversity of countries (Jennissen et al., 2018). Economic inequality is also present in Rotterdam. In 2016, $20 \%$ to $22 \%$ of minors were living in poverty (Hoff, 2017). Moreover, it has a high percentage (54\%) of schools where more than $80 \%$ of the students are non-western migrants (Herweijer, 2008). This "segregation" among schools is reinforced by young people's socio-demographic backgrounds (e.g., parents' education level and their neighborhoods) and it affects their social networks as well as their opportunities because migrant and non-migrant youth are often separated according to the school that they attend (Herweijer, 2008). Despite these inequalities, previous research has shown that $77 \%$ of the population of Rotterdam are proud of their city-a number that has risen from 55\% in 2009 (OBI, 2018). This provides an interesting background when investigating Rotterdam's urban identity, as this positive evaluation underlines the importance of the urban environment.

When one lives in a certain place for a while, one begins to feel attached to the environment, and, in due course, people might start feeling that they belong there. Previous research has, from different disciplines and points of view, focused on a sense of belonging and attachment to a place, which can be central to personal and social identity (Lalli, 1992; Proshansky et al., 1983; Tuan, 1977). Place-identity is constructed through defining oneself in relation to the spatial environments that are central to their everyday lives, which are central to how they understand and experience the world around them (Proshansky et al., 1983; Tuan, 1977). Placeidentity stresses the physical setting of the human being, and how this is perceived in everyday experience and the resulting memories and ideas, without neglecting the individual, interpersonal, and social group factors (Proshansky et al., 1983). Previous research has also focused specifically on the urban environment (Lalli, 1992; Proshansky et al., 1983). Urban identity entails a similar idea to place-identity, yet focuses on the city in particular. Here, the city "provides an identity-enhancing context for one's biography, and thus a continuity which is relatively independent from definite (e.g., social) changes" 
(Lalli, 1992, p. 294). It also helps citizens to differentiate themselves from people in other cities, which creates both an idea of attributes associated with the city, as well as a sense of belonging to a social group (Lalli, 1992).

From a social perspective, Lalli (1992) argues that a sense of "we", and thus belonging to a social group, is created as part of urban identity. Migrant and nonmigrant adolescents may, therefore, feel like they belong to "Rotterdammers" as a social group, and thus selfcategorize as such. Especially in the context of the superdiversity, where many "Rotterdammers" have a migration background, both migrant and non-migrant adolescents may feel like they belong to the city. As migrant adolescents may not easily identify with the host country's national identity or any other (national) identity of other social groups in their lives, it should be easier for them to identify with the city they live in. Thus, we assume:

H 2: Migrant adolescents have higher social identity than non-migrant adolescents.

$\mathrm{H}$ 2a: Migrant adolescents have higher self-categorization than non-migrant adolescents.

$\mathrm{H} 2 \mathrm{~b}$ : Migrant adolescents have higher group self-esteem than non-migrant adolescents.

\subsection{Migration and Media in the Urban Context}

Social media use plays an important role in this identification process (de Block \& Buckingham, 2007; Rydin \& Sjöberg, 2008). Georgiou (2010), who discusses media and place from a diasporic position, emphasizes that identification takes place on various spatial levels: home, city, national, and transnational. These are interconnected and can be combined. For migrants, media allows for identification both on the level of the homeland, particularly through people with a similar background, as well as the often culturally diverse environment of the destination city (Georgiou, 2010). The city, in particular, offers a space where media production can be used as a form of political and cultural representation (Georgiou, 2010). As Georgiou (2010) argues, "[p]erformative urban identities increasingly move away from the national imaginary and media and communications become experimental tools in this process" (p. 31). Here, the nation may become less dominant and central to the debate of identity, and can be replaced with an urban or transnational perspective (Georgiou, 2010, 2014). This can be related to adolescents' everyday social media engagement. Adolescents may have particular media idols, often SMIs, who are from the same city, and perhaps the same cultural or socio-economic background. A YouTube vlogger from Rotterdam, or even the same neighborhood, might, therefore, function as a media idol. Adolescents may also engage in discussion about what it means to live in the city, or rate, praise, or criticize others' content about it. Finally, adolescents may create and share their own content in which they construct and negotiate their urban identity. As the city can be considered part of their iden- tity, this negotiation of identity could be found in their everyday uses of social media. Thus, we assume:

H 3: Social media engagement has positive impact on self-categorization.

H 4: Social media engagement has positive impact on group self-esteem.

Next to the social perspective, urban identity can also be viewed from a personal perspective. This perspective focuses more on the physical and symbolic aspects of this urban identity. It must be said that while this spatial dimension could potentially function as a cause for this identity, this causality is not assumed in our argumentation. It could be argued that if one feels connected to the social group, one might also feel more at home in the city (Lalli, 1992). Following this argumentation, we hypothesize:

H 5: Migrant adolescents have higher urban identity than non-migrant adolescents.

$\mathrm{H}$ 6: Social media engagement has positive impact on urban identity.

H 7: Social identity has positive impact on urban identity.

Finally, belonging to a place or belonging to a group, and thus identifying with it, can be seen as a key factor in a person's self-esteem (Lalli, 1992). However, migrants might lack a stable national and/or cultural identity, which may impact their personal self-esteem. Compared to group self-esteem, personal self-esteem (from here on referred to as "self-esteem") does not belong to one's social identity but can be influenced by it. This raises the following question and hypotheses:

Q 2: Does self-esteem differ between migrant and non-migrant adolescents?

$\mathrm{H}$ 8: Social media engagement has positive impact on self-esteem.

H 9: Social identity has positive impact on self-esteem. H 10: Urban identity has positive impact on self-esteem.

\section{Methods}

\subsection{Sample and Procedure}

Our survey sample was made up of 324 participants, including 160 boys and 159 girls. The ages of the 321 participants who filled this out ranged from 9 to 13 $(M=10.65 ; S D=0.88)$. The father's country of origin (304 reported cases, 35 countries in total) was mostly the Netherlands (51.6\%), Morocco (18.8\%), or Turkey (9.9\%). The mother's country of origin (312 reported cases, 38 countries in total) was quite similar: the Netherlands (51.9\%), Morocco (17\%), and Turkey (8.3\%). Statistics Netherlands (2015) defines individuals as migrants when at least one of their parents was born abroad. This, therefore, includes first- and second- 
generation migrants. Based on this definition, $41.8 \%$ of the participants were migrants and $58.2 \%$ were nonmigrants ( 20 cases could not be allocated to a group because they did not answer this question).

Rotterdam was chosen as our case study because of its super-diverse character in relation to, among others, socio-economic, ethnic, and cultural levels (Statistics Netherlands, 2018a; Vertovec, 2007), as well as its position as a minority-majority city (Jennissen et al., 2018), which both make for an environment that is characterized by various identities and accompanying differences on multiple levels. Moreover, it has a rich (urban) youth culture and articulated identity (Fortuin \& van der Graaf, 2006; JongRRKC, 2008; Kanne \& van Engeland, 2019), demonstrated not only by its many cultural products but also its reported pride among citizens (OBI, 2018). This shows the importance of urban culture and hints towards possible identification with the city. Finally, Rotterdam is located in the Netherlands, a country where almost all inhabitants have internet access (Statistics Netherlands, 2018b; van Deursen \& Helsper, 2015). This widespread access to the internet is crucial in our research, as it provides youth with a relatively equal opportunity to engage with social media.

Our collaboration with three schools from two different neighborhoods in Rotterdam helped us find adolescents from different backgrounds. These ranged from a strong to a weak socio-economical position and differed in the number of migrants (35.9\% versus $78.5 \%$ ) (Statistics Netherlands, 2018a). The data collection took place in November 2018. The survey was conducted in classrooms at the participating schools, using paper and pencils, and took 15-20 minutes to complete. A researcher and a research assistant were present to introduce the survey and the research, inform the participants about the voluntary nature of the survey and answer any possible questions. The first part of the survey asked the participants a number of demographic questions and questions about access to digital devices. The second part focused on questions about social media use, social media engagement, SMIs, and locality of engagement. Finally, the survey included measures for self-esteem, urban identity, and social identity. Afterwards, participants were thanked for their participation.

\subsection{Measures}

All statistical analyses were conducted using SPSS Statistics (v25). Please see the results for more details on each analysis used.

\subsubsection{Access to Digital Devices}

In order to measure access to digital devices, we asked for ownership of certain digital devices and made a distinction between privately owned and shared devices to take into account the privacy of use of such a device. The device options were smartphone, tablet, and com- puter/laptop, as these provide the most options for social media use.

\subsubsection{Social Media Use}

Social media use was measured by presenting a list of social media platforms and a 5-point Likert scale ( 1 = Never; 5 = Always). We based the options for social media platforms on findings regarding the platforms most frequently used by adolescents in the Netherlands: WhatsApp, Facebook, Instagram, YouTube, Twitter, Snapchat, Pinterest, and Musical.ly (recently renamed TikTok) (Kennisnet, 2017; van der Veer, Boekee, \& Peters, 2017). Additionally, to measure general social media usage, the items were merged into one scale (Cronbach's $\alpha=.66$ ).

\subsubsection{Social Media Engagement}

Social media engagement was measured by four questions covering consumption, participation, production, and communication. We created a new measurement tool, asking for each platform if they consume content (viewing), participate (comment/like/rate content), produce content (make their own content and upload it), or communicate (use the platform to communicate with others). Following this, four new variables were calculated based on the sum of all platforms ( $0=$ no platform used, $9=$ all platform used).

\subsubsection{Intensity of Following Local SMI}

Regarding preference of media consumption, participants were asked to list two of their favorite content creators and the platform they follow them on. This same question was also asked for local content creators. In order to use this local SMI measurement in analysis with regards to intensity of following local SMIs, a new variable, named intensity of following local SMI, was calculated counting the number of platforms used for following the first local SMI mentioned, ranging from 0 to 9.

\subsubsection{Self-Esteem}

Self-esteem was measured both on a personal and a social scale. Rosenberg, Schooler and Schoenbach's (1989) 6-item Self-Esteem scale was used to investigate personal self-esteem. This was done using a 4-point Likert ( 1 = Strongly disagree; 4 = Strongly agree). Four of the questions were positive, whereas two were originally negative. To avoid confusion among the young participants, the latter two were rephrased to be positively phrased (Cronbach's $\alpha=.81$ ).

\subsubsection{Urban Identity}

Identification with the city from a personal perspective was assessed using the 4-item sub-scale ("general attach- 
ment") from the Urban Identity scale (Lalli, 1992) because we considered this shorter scale more suitable for adolescents. This was done using a 5-point Likert scale (1 = Strongly disagree; $5=$ Strongly agree; Cronbach's $\alpha=.82$ ).

\subsubsection{Social Identity}

To measure social identity in terms of self-categorization and group self-esteem, two subscales from Ellemers, Kortekaas and Ouwerkerk's (1999) social identity scale were used. To measure a sense of belonging to the city from a social point of view, we used the 3-item self-identification subscale (adapted from Ellemers et al., 1999), which was measured on a 7-point Likert scale ( 1 = Strongly disagree; 7 = Strongly agree). These questions focused on identification with others living in the city or "Rotterdammers" in this case (Cronbach's $\alpha=.76)$. To measure group self-esteem (in context of their cityrelated group) the 4-item group self-esteem subscale (Ellemers et al., 1999) was used, which was also measured on a 7-point Likert scale ( 1 = Strongly disagree; $7=$ Strongly agree; Cronbach's $\alpha=.75)$.

\subsubsection{Demographics}

Socio-demographics such as age, gender, nationality, and education level were also gathered. As a measure for nationality and cultural background, we asked for the participants' parents' country of birth, as a migrant is defined as having at least one parent born in a foreign country (Statistics Netherlands, 2015). In order to establish a better idea of their relationship to the city, we asked for the participants' home neighborhood as well as the length of time that they have lived in the city.

\section{Results}

\subsection{Comparisons between Migrant and Non-Migrant Adolescents}

Chi-Square tests were conducted to see if migrant and non-migrant adolescents have different access to technological devices. Migrant adolescents more frequently reported that they had their own smartphone than nonmigrant adolescents, countering our first hypothesis that non-migrant adolescents have greater access to digital devices. The opposite was found for owning a laptop or a tablet, which was in line with our first hypothesis. Migrant adolescents were less likely to share smartphones, computers, or laptops but more likely to share tablets (See Table 1 for \%).

Independent $t$-tests were conducted to analyze if migrant and non-migrant adolescents differ concerning their social media usage to answer our question of whether migrant and non-migrant adolescents differ in their social media engagement. Facebook, YouTube, and Snapchat were used more frequently by non-migrant adolescents than by migrant adolescents (See Table 2 for all $M s, S D s$, and $t$-values). No further comparisons among social media use frequency were significant.

Independent $t$-tests were run for social media consumption, social media participation, social media pro-

Table 1. Comparison of access to digital devices.

\begin{tabular}{lccc}
\hline Access to digital device & Migrant & Non-migrant & $\mathbf{X}^{\mathbf{2}}(\mathbf{1}, \mathbf{N}=\mathbf{3 0 4})$ \\
\hline Own smartphone & $91.3 \%$ & $78.0 \%$ & $9.62^{* *}$ \\
Own computer/laptop & $29.1 \%$ & $45.8 \%$ & $8.61^{* *}$ \\
Own tablet & $30.7 \%$ & $47.5 \%$ & $8.61^{* *}$ \\
Shared smartphone & $5.5 \%$ & $10.7 \%$ & 2.58 \\
Shared computer/laptop & $67.7 \%$ & $71.8 \%$ & 0.57 \\
Shared tablet & $56.7 \%$ & $41.2 \%$ & $7.08^{* *}$ \\
\hline
\end{tabular}

Notes: ${ }^{*} \mathrm{p}<.05,{ }^{* *} \mathrm{p}<.01,{ }^{* * *} \mathrm{p}<.001$.

Table 2. Ms and SDs for social media usage for all participants.

\begin{tabular}{|c|c|c|c|c|c|c|c|}
\hline \multirow[t]{2}{*}{ Activity } & \multicolumn{2}{|c|}{ Migrants } & \multicolumn{2}{|c|}{ Non-migrants } & \multicolumn{3}{|c|}{ All } \\
\hline & $M$ & $S D$ & $M$ & $S D$ & $t$-test & $M$ & $S D$ \\
\hline WhatsApp & 3.84 & 1.00 & 3.76 & 1.26 & ns & 3.79 & 1.16 \\
\hline Facebook & 1.12 & 0.49 & 1.29 & 0.68 & $2.42 *$ & 1.21 & 0.60 \\
\hline Instagram & 2.74 & 1.46 & 2.53 & 1.52 & ns & 2.60 & 1.49 \\
\hline YouTube & 4.10 & 0.81 & 4.41 & 0.87 & $3.10 * *$ & 4.29 & 0.84 \\
\hline Twitter & 1.08 & 0.39 & 1.20 & 0.63 & ns & 1.14 & 0.53 \\
\hline Snapchat & 2.17 & 1.23 & 2.62 & 1.41 & $2.86 * *$ & 2.41 & 1.35 \\
\hline Musical.ly & 1.92 & 1.37 & 2.25 & 1.55 & ns & 2.09 & 1.49 \\
\hline Pinterest & 1.23 & 0.66 & 1.40 & 1.00 & ns & 1.32 & 0.86 \\
\hline Other & 2.63 & 1.74 & 2.46 & 1.73 & ns & 2.45 & 1.71 \\
\hline
\end{tabular}

Notes: ${ }^{*} p<.05,{ }^{* *} p<.01$. 
duction, social media communication, general social media usage, intensity of following local SMI, selfcategorization, group self-esteem, urban identity, and self-esteem. Comparisons were made between migrants and non-migrant adolescents. Migrant and non-migrant adolescents only differed significantly for urban identity, in line with our fifth hypothesis, yet countering $\mathrm{H} 2$ and answering Q2. Migrant adolescents scored higher on the urban identity than non-migrant adolescents (See Table 3 for $M s, S D s$ and $t$-values). This was in line our fifth hypothesis that urban identity is higher among migrant adolescents, yet countered the second hypothesis that migrants have a higher social identity. It also negatively answered our question on possible differences in self-esteem.

\subsection{Influences on Social Identity}

Multiple linear regression analyses with self-categorization and group self-esteem as criteria were run with migrant status, social media consumption, social media participation, social media production, social media communication, general social media usage, and intensity of following local SMI as predictors. The model for self-categorization did not reach significance, $R^{2}=.050$, $F(9,266)=1.56, p=.129$. This rejects our third hypothesis, as social media engagement did not have a positive impact on self-categorization. For group self-esteem we found a significant model, $R^{2}=.07, F(9,266)=2.07$, $p=.032$. Both confirming and rejecting our fourth hy- pothesis, intensity of following local SMI was found to be a significant positive predictor and social media participation was revealed to be a negative predictor (See Table 4 for all ßs). Social media engagement had both a positive and negative impact on group self-esteem.

\subsection{Influences on Urban Identity}

To analyze influences on urban identity, a multiple linear regression analysis was conducted using social media consumption, social media participation, social media production, social media communication, general social media usage, intensity of following local SMI, self-categorization, and group self-esteem as predictors. The model was found to be significant, $R^{2}=.55$, $F(11,263)=29.48, p<.001$. Positive predictors were selfcategorization, group self-esteem, migrant status, intensity of following local SMI, and general social media usage, confirming our sixth and seventh hypotheses on the positive impact of social media engagement and social identity on urban identity.

Given the significant differences found for the comparison between migrant adolescents and non-migrant adolescents on urban identity, two separate multiple regression analyses were conducted with general social media usage, intensity of following local SMI, selfcategorization, and group self-esteem as predictors.

For migrant adolescents, we found a positive influence of self-categorization and group self-esteem,

Table 3. Ms, SDs and $t$-values for social media usage and engagement, social identity, urban identity, and self-esteem.

\begin{tabular}{|c|c|c|c|c|c|}
\hline & \multicolumn{2}{|c|}{ Migrants } & \multicolumn{2}{|c|}{ Non-migrants } & \multirow[b]{2}{*}{$t$-test } \\
\hline & $M$ & $S D$ & $M$ & $S D$ & \\
\hline social media consumption & 3.05 & 1.26 & 3.30 & 1.47 & ns \\
\hline social media participation & 2.07 & 1.23 & 2.37 & 1.49 & ns \\
\hline social media production & 1.81 & 1.35 & 1.99 & 1.59 & ns \\
\hline social media communication & 1.76 & 1.01 & 2.01 & 1.29 & ns \\
\hline general social media usage & 2.36 & 0.64 & 2.47 & 0.68 & ns \\
\hline intensity of following local SMI & 0.49 & 0.81 & 0.57 & 0.84 & ns \\
\hline self-categorization & 4.82 & 1.39 & 4.55 & 1.67 & ns \\
\hline group self-esteem & 5.26 & 1.17 & 5.23 & 1.25 & ns \\
\hline urban identity & 4.20 & 0.76 & 3.91 & 0.91 & $2.86 * *$ \\
\hline self-esteem & 3.12 & 0.49 & 3.20 & 0.51 & ns \\
\hline
\end{tabular}

Note: ${ }^{* *} p<.01$.

Table 4. Predictors for self-categorization and group self-esteem.

\begin{tabular}{lcr}
\hline & Self-categorization B & Group self-esteem ß \\
\hline migrant status & -.08 & -.01 \\
social media consumption & .08 & .15 \\
social media participation & -.06 & $-.22 *$ \\
social media production & -.04 & .08 \\
social media communication & -.14 & -.14 \\
general social media usage & .02 & -.04 \\
intensity of following local SMI & .10 & $.13 *$ \\
\hline
\end{tabular}

Note: ${ }^{*} p<.05$. 
$R^{2}=.46, F(4,120)=25.15, p<.001$. For non-migrant adolescents, self-categorization and group self-esteem were again found to have a positive impact on urban identity. In addition, intensity of following local SMI was also found to be a positive predictor, $R^{2}=.53$, $F(4,171)=48.93, p<.001$ (See Table 5 for all ßs).

\subsection{Influences on Self-Esteem}

Self-esteem was analyzed using a multiple linear regression analysis with social media consumption, social media participation, social media production, social media communication, general social media usage, intensity of following local SMI, self-categorization, group selfesteem, and urban identity as predictors. The model reached significance, $R^{2}=.15, F(12,260)=3.81, p<.001$. The only positive predictor found was self-categorization, partly in line with our ninth hypothesis, but at the same time countering it, as well as our eighth hypothesis on the positive impact of social media engagement and the tenth hypothesis on the positive impact of urban identity (See Table 6 for all ßs).

\section{Discussion}

This study investigated the social media engagement and identity development of adolescents in the superdiverse city of Rotterdam and analyzed the potential differences between migrant and non-migrant adolescents. We found that migrant adolescents more often had their own smartphone and shared a tablet than non-migrant adolescents $(\neq \mathrm{H} 1)$, yet non-migrant adolescents had more access to their own computer/laptop and tablet $(=\mathrm{H} 1)$. The higher number of smartphones among migrant adolescents could, to a certain extent, be explained by the important role of the phone- and internet access in the experience of migration through, for instance, keeping in touch with family, as was found in previous research (Alencar, 2018; de Leeuw \& Rydin, 2007). This difference could also be explained by socioeconomic differences, as well as parental mediation (Livingstone, Mascheroni, Dreier, Chaudron, \& Lagae, 2015; van Dijk, 2012). Computers, laptops, and tablets are generally more expensive than smartphones. Smartphones can also be hand-me-downs from other family members, while some parents may consciously try to restrict their child's digital media use (Livingstone et al., 2015). Investigating social media engagement differences between migrant and non-migrant adolescents (Q1), analysis showed that non-migrant adolescents were more likely to use Facebook, YouTube and Snapchat than migrant adolescents.

In terms of (urban) identity construction, we differentiated between social identity, urban identity, and self-esteem. We found no differences for social identity between the two groups, both in terms of self-

Table 5. Predictors for urban identity.

\begin{tabular}{llcc}
\hline Urban identity & All ß & Migrant ß & Non-migrant ß \\
\hline migrant status & $-.13^{* *}$ & - & - \\
social media consumption & -.06 & - & - \\
social media participation & -.02 & - & - \\
social media production & -.12 & - & - \\
social media communication & -.06 & .10 & - \\
general social media usage & $.13^{*}$ & .06 & -.01 \\
intensity of following local SMI & $.13^{* *}$ & $.12^{*}$ \\
self-categorization & $.53^{* * *}$ & $.51^{* * *}$ & $.16^{* *}$ \\
group self-esteem & $.16^{* *}$ & $.22^{*}$ &
\end{tabular}

Notes: ${ }^{*} p<.05,{ }^{* *} p<.01,{ }^{* * *} p<.001$.

Table 6. Predictors for self-esteem.

\begin{tabular}{lr}
\hline & self-esteem $\mathbf{B}$ \\
\hline migrant status & .09 \\
social media consumption & -.03 \\
social media participation & .18 \\
social media production & .04 \\
social media communication & -.01 \\
general social media usage & .03 \\
intensity of following local SMI & .01 \\
self-categorization & $.22 *$ \\
group self-esteem & .08 \\
urban identity & .01 \\
\hline
\end{tabular}

Note: ${ }^{*} p<.05$. 
categorization and group self-esteem ( $\neq \mathrm{H} 2, \mathrm{H} 2 \mathrm{a}, \mathrm{H} 2 \mathrm{~b}$ ). Social media engagement did not have an influence on self-categorization $(\neq \mathrm{H} 3)$. When investigating the influences of social media engagement on social identity, we found that following local SMIs positively predicted $(=\mathrm{H} 4)$ and social media participation negatively predicted $(\neq \mathrm{H} 4)$ group self-esteem. Following local SMIs may help to construct a local identity, as adolescents might find the SMIs to be similar to them. When following these media idols from the same city, adolescents may feel a sense of pride or shared identity, focusing on the idea that they both live in the same city-something that binds them and creates a sense of "us" (Lalli, 1992). On the other hand, social media participation might be directed at a larger, perhaps more global audience and the evaluation of their content. While liking, commenting, and sharing, adolescents may find also themselves comparing, contrasting, and judging. Social media engagement might, therefore, inspire a more critical stance towards one's own local social group. Previous research has also found a reversed argument: those with a negative group self-esteem used social media to engage with others outside the group (Barker, 2009). This could mean that those who are not fond of the city and its inhabitants might aim to actively engage with content that is not related to this group.

Urban identity was found to be significantly higher among migrant adolescents than non-migrant adolescents (= H5). This could be explained by the fact that migrant adolescents, having different national backgrounds than the one they currently live in, may have less coherent national identities in comparison to non-migrant adolescents. Therefore, our participants identified more strongly with Rotterdam, when asked, than they might when relating themselves to wider notions of identity, such as a Dutch national identity. This is in line with earlier research pointing out the significance of the city in the migration process, as well as the identification on different spatial levels (Georgiou, 2010; Rydin \& Sjöberg, 2008). While identifying on one particular spatial level does not exclude identification on the other levels, and identification on one spatial level is not limited to one particular place (as proven by hybrid identities) (Georgiou, 2010; Lalli, 1992; Rydin \& Sjöberg, 2008), the significance of the city in the everyday lives of the individual, particularly in the case of a migrant (Georgiou, 2010), may strengthen that sense of belonging. This may especially be the case in a super-diverse majority-minority city, where individuals are generally surrounded by others with similarly diverse identities.

The intensity of following local SMI and general social media usage were positive predictors of urban identity for both groups $(=\mathrm{H} 6)$. The influence of SMIs on identity, particularly as role models and inspiration, is in line with research in other fields (Gomillion \& Giuliano, 2011). When one's media idol, a person that is often admired, lives in the same city, this may foster a sense of similarity and recognition, and, as a result, a sense of belonging.
Just as is the case with other citizens (Lalli, 1992), the influencer may become important to the individual's identity construction through the construction of "us" versus "them", differentiating themselves from other people outside the city (Lalli, 1992). This also connects to the idea that adolescents prefer media idols similar to themselves whom they can identify with (Valkenburg \& Piotrowski, 2017).

In terms of social identity, it was found that both selfcategorization and group self-esteem were positive predictors of urban identity (= H7). This suggests that if one feels like one belongs to the group of "Rotterdammers", and when they feel good about this group, they also identify with the city personally. This is in line with the argument that well-being is connected to the urge to belong to a social group (Lalli, 1992). Moreover, it also supports the previous argument that the super-diverse group of citizens harbors a sense of similarity in its differences.

When testing separately for migrant and non-migrant adolescents, notable results were found. While for both group self-categorization and group self-esteem remained a positive impact on urban identity, differences were found in the impact social media engagement had on urban identity. The intensity of following local SMI was only a positive predictor for non-migrant adolescents. This might be explained by the finding that migrants already have a higher urban identity than nonmigrants, possibly due to previously mentioned reasons, and therefore the intensity of following local SMI cannot increase urban identity much more. Non-migrant adolescents, on the other hand, might feel more connected to the city when they engage with local influencers who may strengthen their sense of belonging, as previously argued.

Finally, we found no difference for self-esteem between migrant and non-migrant adolescents (Q2). When analyzing possible influences on self-esteem, only selfcategorization was found to be a positive predictor (= H9), whereas group self-esteem, social media engagement, and urban identity were not $(\neq \mathrm{H} 9, \neq \mathrm{H} 8, \neq \mathrm{H} 10)$. Self-categorizing with the local social group could create a sense of belonging, which is connected to the promotion of self-esteem (Lalli, 1992). Resulting from our previous argumentation on urban identity, one could expect self-esteem to be higher for migrants as a result. However, our results go against the idea that high urban identity results in high individual self-esteem. This could be due to the complexity of self-esteem, especially in the life of migrants, where numerous other factors, such as ethnic background and socio-economic status, may also play important roles (Rumbaut, 1994).

\section{Conclusion}

This study investigated adolescents' urban identity from a personal and social perspective and related this to their social media use. Building on the notion of urban identity (Lalli, 1992; Proshansky et al., 1983), and positioning 
this in a framework of the super-diverse city (Vertovec, 2007), as a central space for the negotiation of identity of migrants and non-migrants (Georgiou, 2010; Lalli, 1992), we have found that this urban identity is particularly present among migrant adolescents. Here, social media engagement plays different roles, mostly positively associated with various forms of identity and self-esteem, yet, in one case, also negatively. Furthermore, differences were found between migrant and non-migrant adolescents in terms of access to digital devices and their preferences for social media platforms.

In this project, we have been able to gather data from migrant adolescents-a group generally hard to reach in survey research. The colorful survey, adapted to the interests of this particular age group, worked well in the school setting in which the surveys were conducted. The results may have important implications for studying the well-being of young migrants in super-diverse cities, where urban identity should be taken into account as an important factor in settling in and dealing with differences surrounding them. Taking into account urban identity might be particularly crucial to research involving migrant adolescents who have just arrived in the new city, as they may have to reestablish a sense of belonging in a new place. Having access to and using these social media might prove an essential tool for identity development and for creating a sense of belonging. Finally, future research should investigate in more detail how social media use and engagement plays a role in the construction of the urban identity.

This study has several limitations. The first one entails the distinction made between migrants and nonmigrants. Migrants are not a homogeneous group and differ according to their reasons for migration, cultural background, socio-economic status, and the length of time that they have lived in the country (de Block \& Buckingham, 2007; Jennissen et al., 2018). Future research should, therefore, take into account the length of residence when investigating the strength of experienced urban identity. Second, due to the age of the target group, the length of the survey prohibited in-depth questions about engagement. More in-depth research on social media engagement on particular platforms could give a more complete image of the types of social media use among different groups in society. Thirdly, it should be noted that the model for self-categorization did not reach significance, and the variance was relatively limited. Assumptions on the relationship between urban identity, social identity, self-esteem and social media engagement were based on theory. However, due to the cross-sectional nature of our study, causal assumptions are difficult to make. Finally, this research does not explain differences in urban identity between groups. A qualitative study could further investigate how adolescents actively identify with the city by engaging them in making media content about their own situation. All in all, this survey has contributed to the literature on online identity construction among adolescents in super-diverse cities. While some of the findings proved to be largely in line with existing research, our survey has demonstrated that theory can be enriched by incorporating urban identity as part of the identity development of young people in urban environments, particularly in the case of migrant adolescents. As our findings have shown that urban self-categorization is a positive predictor of personal self-esteem, urban identity might play an important role in adolescent empowerment, in which social media is used as a tool for this creation and negotiation of identity.

\section{Acknowledgments}

We would like to thank Ray Borggreve for connecting us and helping us during the project. We would also like to thank the participating schools and teachers involved for their willingness to help and participate.

\section{Conflict of Interests}

The authors declare no conflict of interests.

\section{References}

Alencar, A. (2018). Refugee integration and social media: A local and experiential perspective. Information, Communication and Society, 21(11), 1588-1603. https://doi.org/10.1080/1369118X.2017.1340500

Anderson, M., \& Jiang, J. (2018). Teens, social media \& technology 2018. Pew Research Center. Retrieved from https://www.pewinternet.org/2018/05/31/ teens-social-media-technology-2018

Barker, V. (2009). Older adolescents' motivations for social network site use: The influence of gender, group identity, and collective self-esteem. CyberPsychology \& Behavior, 12(2), 209-213. https://doi.org/ $10.1089 /$ cpb.2008.0228

boyd, d. (2014). It's complicated: The social lives of networked teens. New Haven, CT: Yale University Press.

boyd, d., \& Ellison, N. B. (2007). Social network sites: Definition, history, and scholarship. Journal of ComputerMediated Communication, 13(1), 210-230. https:// doi.org/10.1111/j.1083-6101.2007.00393.x

Brake, D. R. (2014). Are we all online content creators now? Web 2.0 and digital divides. Journal of Computer-Mediated Communication, 19(3), 591-609. https://doi.org/10.1111/jcc4.12042

Carr, C. T., \& Hayes, R. A. (2015). Social media: Defining, developing, and divining. Atlantic Journal of Communication, 23(1), 46-65. https://doi.org/10.1080/ 15456870.2015 .972282

de Block, L., \& Buckingham, D. (2007). Global children, global media: Migration, media and childhood. New York, NY: Palgrave Macmillan.

de Leeuw, S., \& Rydin, I. (2007). Migrant children's digital stories: Identity formation and self-representation through media production. European Journal of Cul- 
tural Studies, 10(4), 447-464. https://doi.org/10. $1177 / 1367549407081948$

Delfos, M. F. (2013). The virtual environment from a developmental perspective. In B. Heys, M. Matthes, \& P. Sullivan (Eds.), Improving the quality of childhood in Europe 2013 (Vol. 4). East Sussex: ECSWE. Retrieved from http://www.allianceforchildhood.eu/ improving-the-quality-of-childhood-in-europe-2013volume-4

Ellemers, N., Kortekaas, P., \& Ouwerkerk, J. W. (1999). Self-categorisation, commitment to the group and group self-esteem as related but distinct aspects of social identity. European Journal of Social Psychology, 29(2/3), 371-389. https://doi.org/10.1002/ (SICI)1099-0992(199903/05)29:2/3<371::AID-EJSP9 32>3.0.CO; $2-U$

Fortuin, K., \& van der Graaf, P. (2006). De stad verhaalt van de stad: Rotterdamse lokale identiteit en cultuur als hulpbron [The city's tale of the city: Rotterdam local identity and culture as a resource]. Utrecht: Verwey-Jonker Instituut. Retrieved from https:// www.verwey-jonker.nl/doc/vitaliteit/D3472246.pdf

Georgiou, M. (2010). Identity, space and the media: Thinking through diaspora. Revue Européenne Des Migrations Internationales, 26(1), 17-35. https://doi. org/10.4000/remi.5028

Georgiou, M. (2014). Diaspora in the digital era: Minorities and media representation. Journal on Ethnopolitics and Minority Issues in Europe, 12(4), 80-99. Retrieved from https://www.ecmi.de/publications/ jemie

Gomillion, S. C., \& Giuliano, T. A. (2011). The influence of media role models on gay, lesbian, and bisexual identity. Journal of Homosexuality, 58(3), 330-354. https://doi.org/10.1080/00918369.2011.546729

Herweijer, L. (2008). Segregatie in het basis- en voortgezet onderwijs [Segregation in primary- and secondary education]. In P. Schnabel, R. Bijl, \& J. de Hart (Eds.), Betrekkelijke betrokkenheid: Studies in sociale cohesie [Relative engagement: Studies in social cohesion] (pp. 206-233). The Hague: Sociaal Cultureel Planbureau. Retrieved from https://www.scp.nl/Publicaties/Alle_publicaties\% 09/Publicaties_2014/Verschil_in_Nederland

Hoff, S. (2017). Armoede onder kinderen: Een probleemschets [Poverty among children: An outline of the problem]. The Hague: Sociaal Cultureel Planbureau. Retrieved from https://www.scp.nl/Publicaties/ Alle_publicaties/Publicaties_2017/Armoede_onder_ kinderen

Ito, M., Baumer, S., Bittanti, M., boyd, d., HerrStephenson, B., Horst, H. A., . . . Tripp, L. (2010). Hanging out, messing around and geeking out. Cambridge, MA: MIT Press.

Jansz, J., Slot, M., Tol, S., \& Verstraeten, R. (2015). Everyday creativity: Consumption, participation, production, and communication by teenagers in the Netherlands. Journal of Children and Media, 9(2), 143-159. https://doi.org/10.1080/17482798.2015.1015433

Jennissen, R., Engbersen, G., Bokhorst, M., \& Bovens, M. (2018). De nieuwe verscheidenheid: Toenemende diversiteit naar herkomst in Nederland [The increasing diversity: Increasing diversity in origin in The Netherlands]. The Hague: Wetenschappelijke Raad voor het Regeringsbeleid.

JongRRKC. (2008). What's the 411 in Rotterdam? Rotterdam: Rotterdamse Raad voor Kunst \& Cultuur.

Kanne, P., \& van Engeland, W. (2019). Regio- \& provinciegevoel [Sense of region- \& province]. Amsterdam: I\&O Research. Retrieved from https:// ioresearch.nl/Portals/0/Rapport\%20lenO\%20NOS2\% 20Regiogevoel\%20def_1.pdf

Kennisnet. (2017). Monitor jeugd en media 2017 [Monitor youth and media 2017]. Retrieved from https://www.kennisnet.nl/publicaties/monitorjeugd-en-media

Kushner, S. (2016). Read only: The persistence of lurking in Web 2.0. First Monday, 21(6). https://doi.org/ 10.5210/fm.v21i6.6789

Lalli, M. (1992). Urban-related identity: Theory, measurement, and empirical findings. Journal of Environmental Psychology, 12(4), 285-303. https://doi.org/10. 1016/S0272-4944(05)80078-7

Leurs, K., Omerović, E., Bruinenberg, H., \& Sprenger, S. (2018). Critical media literacy through making media: A key to participation for young migrants? Communications, 43(3), 427-450. https://doi.org/10.1515/ commun-2018-0017

Livingstone, S., Mascheroni, G., Dreier, M., Chaudron, S., \& Lagae, K. (2015). How parents of young children manage digital devices at home: The role of income, education and parental style. London: EU Kids Online. Retrieved from http://www.Ise.ac.uk/ media@lse/research/EUKidsOnline/EUKidsIV/PDF/ Parentalmediation.pdf

Nielsen, J. (2006). The 90-9-1 rule for participation inequality in social media and online communities. Nielsen Norman Group. Retrieved from https://www. nngroup.com/articles/participation-inequality

OBI. (2018). Feitenkaart Rotterdammers over hun stad: Omnibusenquête 2017 [Factsheet Rotterdammers about their city: Omnibus survey]. Rotterdam: Gemeente Rotterdam. Retrieved from https://rotterdam.buurtmonitor.nl/documents

Proshansky, H. M. (1978). The city and self-identity. Environment and Behavior, 10(2), 147-169. https://doi. org/10.1177/0013916578102002

Proshansky, H. M., Fabian, A. K., \& Kaminoff, R. (1983). Place-identity: Physical world socialization of the self. Journal of Environmental Psychology, 3(1), 57-83. https://doi.org/10.4324/9781315816852

Rosenberg, M., Schooler, C., \& Schoenbach, C. (1989). Self-esteem and adolescent problems: Modeling reciprocal effects. American Sociological Review, 54(6), 1004-1018. Retrieved from http://www.jstor.org/ stable/2095720 
Rumbaut, R. G. (1994). The crucible within: Ethnic identity, self-esteem, and segmented assimilation among children of immigrants. International Migration Review, 28(4), 748-794. https://doi.org/10. $2307 / 2547157$

Rydin, I., \& Sjöberg, U. (2008). Internet as a communicative space for identity construction among diaspora families in Sweden. In I. Rydin \& U. Sjöberg (Eds.), Mediated crossroads: Identity, youth culture and ethnicity. Göteborg: Nordicom.

Shao, G. (2009). Understanding the appeal of user-generated media: $A$ uses and gratification perspective. Internet Research, 19(1), 7-25. https:// doi.org/10.1108/10662240910927795

Statistics Netherlands. (2015). Migranten, vreemdelingen en vluchtelingen: Begrippen op het terrein van asiel en buitenlandse migratie [Migrants, foreigners, and refugees: Concepts in the field of asylum and foreign migration]. Statistics Netherlands. Retrieved from https://www.cbs.nl/nl-nl/achtergrond/2012/ 43/migranten-vreemdelingen-en-vluchtelingen-

begrippen-op-het-terrein-van-asiel-en-buitenlandsemigratie

Statistics Netherlands. (2018a). Bevolking; leeftijd, migratieachtergrond, geslacht en regio, 1 januari [Population; age, migration background, gender, and region, January 1]. Statistics Netherlands. Retrieved from https://opendata.cbs.nl/\#/CBS/nl/dataset/ $37713 /$ table?ts $=1544456706377$

Statistics Netherlands. (2018b). Internet; toegang, ge- bruik en faciliteiten [Internet; access, use, and facilities]. Statistics Netherlands. Retrieved from http:// statline.cbs.nl/Statweb/publication/?DM=SLNL\&PA= 83429ned\&D1=0\&D2=0,3-6\&D3=0\&D4=a\&VW=T

Tuan, Y. F. (1977). Space and place: The perspective of experience. London: University of Minnesota Press.

Valkenburg, P. M., \& Peter, J. (2011). Online communication among adolescents: An integrated model of its attraction, opportunities, and risks. Journal of Adolescent Health, 48(2), 121-127. https://doi.org/ 10.1016/j.jadohealth.2010.08.020

Valkenburg, P. M., \& Piotrowski, J. T. (2017). Plugged in: How media attract and affect youth. New Haven, CT: Yale University Press.

van der Veer, N., Boekee, S., \& Peters, O. (2017). Nationale social media onderzoek 2017 [National social media research 2017]. Amsterdam: Newcom Research \& Consultancy. Retrieved from https://www. newcom.nl/socialmedia2017?page=socialmedia2017

van Deursen, A. J. A. M., \& Helsper, E. J. (2015). The thirdlevel digital divide: Who benefits most from being online. Communication and Information Technologies Annual, 10, 29-52. https://doi.org/10.1108/S2050206020150000010002

van Dijk, J. A. G. M. (2012). The network society (3rd ed.). London: Sage.

Vertovec, S. (2007). Super-diversity and its implications. Ethnic and Racial Studies, 30(6), 1024-1054. https:// doi.org/10.1080/01419870701599465

\section{About the Authors}

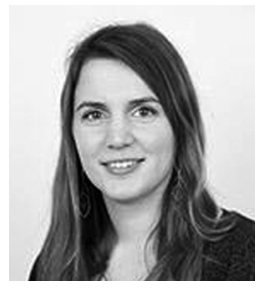

Anne K. van Eldik, MA, MSc is a PhD Candidate at the Erasmus Research Centre for Media, Communication and Culture (ERMeCC) at the Erasmus University Rotterdam. Her current research interests include media engagement, the role of social media in identity construction among adolescents, and creative media use in an urban context, as well as the role of social media in the (re)building of social capital.

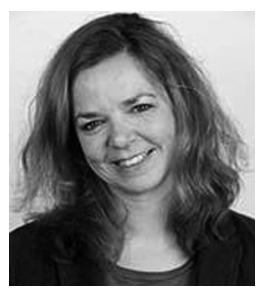

Julia Kneer, PhD, is currently working as an Assistant Professor at the Erasmus University Rotterdam, Erasmus School of History, Culture and Communication. She studied Psychology at Saarland University, received her PhD in Social Psychology in 2006 and her Habilitation in 2013. Her research focus lies in digital games, health communication, music perception, social cognition, and media usage and effects in general.

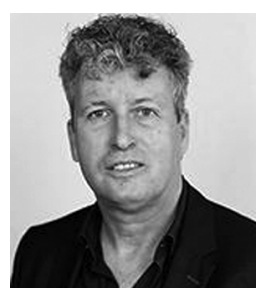

Jeroen Jansz, PhD, holds the Chair of Communication and Media in the Department of Media \& Communication at Erasmus University Rotterdam and is a member of the Erasmus Research Centre for Media, Communication, and Culture. His research is about the reception of social media. Jansz has (co-) authored about 45 international scientific publications and 3 international books, and around 30 scientific publications and 4 books in Dutch. For an overview see http://jeroenjansz.nl/ 